\title{
INFANT- AND YOUNG CHILD-FEEDING PRACTICES IN MONGOLIA
}

\author{
Otgonjargal D. ${ }^{1 *}$, Batjargal J. ${ }^{1}$, Davaalkham D. ${ }^{2}$, Gereljargal B. ${ }^{1}$ \\ ${ }^{1}$ National Center of Public Health, Mongolia \\ ${ }^{2}$ Department of Epidemiology and Biostatistics School of Public Health, \\ National Medical Sciences University, Mongolia \\ *corresponding author, email: otgondamdin70@gmail.com
}

\begin{abstract}
For almost all infants, breastfeeding remains the simplest, healthiest and least expensive feeding method that fulfils the infants' needs. To assess the indicators of infant and young child feeding practices among 0- 23 months old children.

This cross-sectional studies was conducted all 21 provinces of the 4 economic regions of the country and capital Ulaanbaatar city. A total of 350 children aged 0-23 months were selected from sampled households. In total, 350 children aged less than two years selected through revised 125-cluster sampling using of the indicators for assessing infant and young child feeding (IYCF) practices were revised during the International Consensus Meeting organized be WHO in 2007.

The proportions of infants with early initiation of breastfeeding (85.5\%) and exclusive breastfeeding at the age of 4-5 months (46.7\%) were low and infants who received foods from four and more groups is insufficient in Western and Eastern regions. Consumption of vegetables and fruits was also insufficient. Dairy products (milk, yogurt, cheese and other dairy products) were included in the diet of 75.6\% (95\%CI 69.2-81.0) of 6-23 month-old children during the previous day $(p<0.003)$.

The main problems revealed from the study were inappropriate complementary feeding practices. Our findings have highlighted the need to encourage mothers to enrich their traditional wheat-based complementary foods add more animal source foods and vegetables.
\end{abstract}

Keywords: Breastfeeding; Child-feeding practices; Early initiation of breastfeeding; Exclusive breastfeeding; Infant-feeding practices;

\section{INTRODUCTION}

Breast milk is the natural nutrition for all infants. According to the American Academy of Pediatrics (AAP), it is the preferred choice of feeding for all infants ${ }^{1}$. The World Health Organization (WHO) recommends exclusive breastfeeding for the first six months of life with early initiation and continuation of breastfeeding for two years or more together with nutritionally-adequate, safe, ageappropriate complementary feeding starting at six months ${ }^{2}$. The WHO and United Nations Children Fund have articulated a global strategy for infant- and young child-feeding. Optimal infant- and young child-feeding (IYCF) practices are crucial for nutritional status, growth, development, health, and ultimately the survival of infants and young children ${ }^{3-5}$. Worldwide, suboptimal breastfeeding still accounts for deaths of 1.4 million children aged less than five years (under-five mortality). 
The timely introduction of complementary feeding can prevent almost $6 \%$ of underfive mortality6. It was estimated that, if $90 \%$ of infants are covered with a package of intervention to protect, promote, and support the optimal IYCF practices, almost one-fifth of overall under-five mortality can be averted ${ }^{6}$. The poor complementary feeding practices mean that many children continue to be vulnerable to irreversible outcomes of stunting, poor cognitive development, and significantly increased risk of infectious diseases, such as diarrhoea and acute respiratory infection $5,7,8$.

\section{MATERIALS AND METHODS}

The population based, cross-sectional descriptive study was conducted all 21 provinces of the 4 economic regions of the country and capital Ulaanbaatar city among children aged less than two years during July- August 2010 using the two stage revised 125-cluster sampling technique. Trained interviewers collected information on age, sex, and feeding practices of the study children by interviewing mothers/other responsible caregivers at their home. Definitions formulated by the WHO for indicators of the IYCF practices were used ${ }^{19}$.

Analysis of data Survey data was analysed

\section{RESULTS: Infant feeding patterns}

Although breastfeeding was universal, only $85.5 \%$ of the study children were put to the breast within one hour of birth. About $14.5 \%$ of the neonates $(n=50)$ had to wait for at least 24 hours for first sips of breast milk.
The benefits of breastfeeding in reducing the risk of infection and mortality and improving growth in the first 6 months of life have been known for some time ${ }^{9,10}$.

In Mongolia the indicator on exclusive breastfeeding in the first six months of life is only $38.3 \%$, whereas it is $79.7 \%$ until 4 months old. The fact that of the children 6-59 months $83.5 \%$ were put to the breast within one hour of the birth. The average period of exclusive breastfeeding is $4.87 \pm 2.19$ months and the average period of continuous breastfeeding is $19.28 \pm 10.63$ months $^{17}$.

using PASW statistics 18.0 and EPI INFO 2000 software. Frequencies of categorical variables and mean averages of continuous variables were calculated along with $95 \%$ confidence interval. For calculation of overall measures for the entire survey sample, analyses were stratified by region. The statistical significance of differences in prevalence and measures of central tendency between subgroups were calculated using, 95\% confidence interval and chi-square $\mathrm{p}$ value.

Ethics The Ethics Committee under the auspices of the Ministry of Health approved the study.

The proportion of children with early initiation of breastfeeding is statistically significantly higher in Western Region than in Central and Eastern Regions and Ulaanbaatar.

Table 1. Initial breastfeeding practices of study children according to age and sex

\begin{tabular}{lccc}
\hline $\begin{array}{c}\text { Age (months) and } \\
\text { sex }\end{array}$ & Total & Early initiation & $\begin{array}{c}\chi^{2} \\
\text { (p value) }\end{array}$ \\
\hline $0-5$ & & & \\
Male & 47 & $41(86.6)$ & 0.06 \\
Female & 34 & $29(85.8)$ & $(0.801)$ \\
Total & 81 & $70(86.4)$ & $\mathrm{df}=1$ \\
\hline 6-11 & 43 & $36(84.0)$ & 0.44 \\
Male & & $-56-$ &
\end{tabular}




$\begin{array}{lccc}\begin{array}{l}\text { Female } \\ \text { Total }\end{array} & 44 & 39(87.7) & (0.506) \\ \mathrm{df}=1\end{array}$

The difference between age-groups in the proportion of children having early initiation of breastfeeding, although not significant and sex was not associated with early initiation of breastfeeding is shown in Table 1.

Feeding of $0-5$ months old children children aged 0-5 months, $28.7 \%$ (95\% CI
18.8- 41.2, $\mathrm{p}<0.053)$ were receiving solid, semi-solid foods or liquid (e.g. water, juice, or other foods) other than breast milk.

Age appropriate breastfeeding: Of children 0-23 months of age, $78.6 \%$ (95\%CI 73.183.3) were breastfed at the time of the data collection.

Table 2. Age appropriate breastfeeding of children aged 0-23 months, by region

\begin{tabular}{|c|c|c|c|}
\hline Region & $\mathrm{N}$ & $\%$ & $95 \% \mathrm{CI}$ \\
\hline Western & 59 & 93.7 & $84.5-97.6$ \\
\hline Khangai & 59 & 80.8 & $69.0-88.9$ \\
\hline Central & 52 & 75.7 & $64.9-83.5$ \\
\hline Eastern & 65 & 77.4 & $66.3-85.6$ \\
\hline Ulaanbaatar & 46 & 74.2 & $62.2-83.4$ \\
\hline
\end{tabular}

The percent of children currently breastfeeding at the time of survey data collection was statistically significantly greater in Western Region than in other regions. The prevalence of current breastfeeding in $0-23$ month old children was $80.2 \%$ (95\%CI 73.3 $85.6)$ in rural and $77.5 \%(95 \% \mathrm{CI} 69.2-84.1)$ in urban area.

\section{Exclusive breastfeeding:}

Overall, $71.3 \%$ of the infants aged less than six months were exclusively breastfed. The exclusive breastfeeding rate dropped from $98.0 \%$ in infants aged less than two months to $85.8 \%$ at $2-3$ months and $46.7 \%$ at $4-5$ months of age in table 3 . This decrease in exclusive breastfeeding rates with age was statistically significant.

Table 3. Exclusive breastfeeding, by age groups

\begin{tabular}{|l|c|c|c|c|}
\hline \multirow{2}{*}{$\begin{array}{c}\text { Age groups } \\
\text { (months) }\end{array}$} & \multirow{2}{*}{$\mathrm{N}$} & \multicolumn{3}{|c|}{ Exclusive breastfeeding } \\
\cline { 3 - 5 } & & $\mathrm{n}$ & $\%$ & $95 \% \mathrm{CI}$ \\
\hline $0-1$ & 22 & 21 & 98.0 & $87.0-99.7$ \\
\hline $2-3$ & 25 & 19 & 85.8 & $67.7-94.6$ \\
\hline $4-5$ & 33 & 17 & 46.7 & $29.2-65.1$ \\
\hline
\end{tabular}


As shown in Figure 1 the prevalence of exclusive breastfeeding in $0-5$ month old children was higher in the Central Region
(93.3) than in other regions; however, this difference was clearly statistically significant only with the Eastern Region.

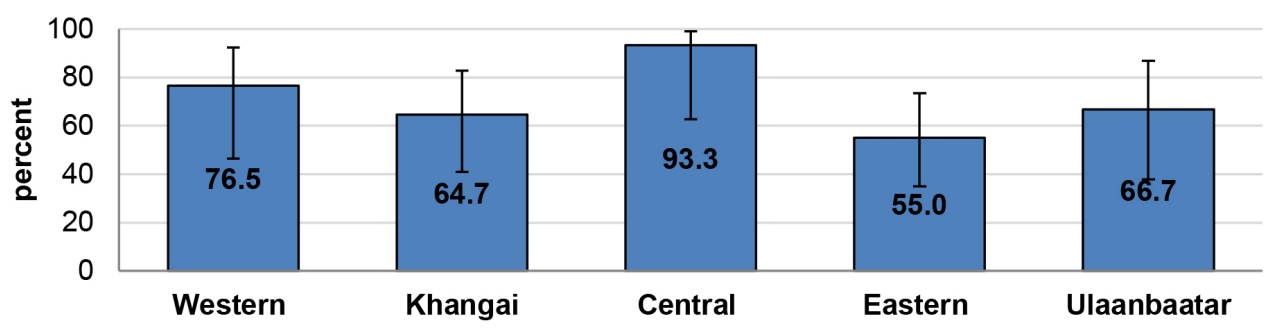

Figure 1. Exclusive breastfeeding, by region

The percent of 0-5 month old children who were exclusively breastfed was $69.1 \%(95 \% \mathrm{CI}$ 50.6-83.0) in urban settings and $74.2 \%(95 \% \mathrm{CI}$ 57.7-85.9) in rural settings.

Continued breastfeeding at 2 years: Of the surveyed children aged 20-23 months, 54.6\% (95\%CI 39.6- 68.8) were still breastfeeding at the time of survey data collection.

Duration of breastfeeding: Median

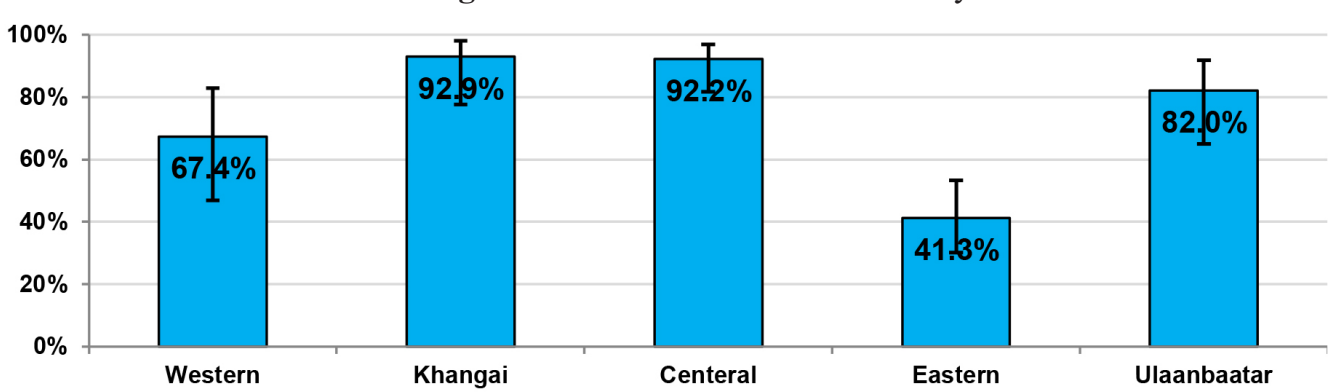

duration of breastfeeding was 14.1 months in 0-59 months old children; 12.8 months in $0-35$ months old children.

\section{Complementary feeding}

Complementary feeding frequency of 6-23 month-old children: Of the surveyed children aged 6-23 months, $80.8 \%$ (95\%CI 73.6-86.3) were fed complementary food at a frequency recommended by WHO.

Figure 2. Percent of children aged 6-23 months who are fed at frequency appropriate for their age, by region

The proportion of children who were fed at a frequency appropriate for their age was lowest in Eastern Region, intermediate in Western Region, and higher in Ulaanbaatar, Khangai, and Central Regions. The differences between Eastern Region and Central and Khangai Region and Ulaanbaatar were statistically significant $(\mathrm{p}<0.05)$ (Figure 2).

In urban settings, $83.3 \%(95 \% \mathrm{CI} 72.3,90.5)$ of children were fed at a frequency appropriate for their age; in rural settings, $77.0 \%(95 \% \mathrm{CI}$ $66.8-84.8)$ of children were fed appropriately for their age. There was little difference by age in appropriate feeding frequency: $81.7 \%$ (95\%CI $71.0-89.1)$ of children aged $6-11$ months, $81.0 \%$ (95\%CI $68.2-89.4)$ of children aged $12-17$ months, and $79.6 \%$ (95\%CI 68.087.7 ) of children aged $18-23$ months were fed at a frequency appropriate for their age.

Food consumption in children 6-23 months of age: Flesh foods and grains are the dominant complementary foods given to surveyed children, while the consumption of legumes and nuts and eggs was rare (Table 3 ). 
Table 3. Food groups consumed by children 6-23 months of age

\begin{tabular}{|lcccc|}
\hline \multicolumn{1}{|c|}{ Food groups } & $\mathrm{n}$ & $\%$ & $95 \% \mathrm{CI}$ \\
\hline Grains, roots and tubers & 246 & 92.0 & $87.5-94.9$ \\
\hline Legumes and nuts & 9 & 3.6 & $1.6-7.5$ \\
\hline Milk and dairy products & 204 & 75.6 & $69.2-81.0$ \\
\hline Flesh foods & 245 & 92.2 & $86.9-95.4$ \\
\hline Eggs & 11 & 5.0 & $2.7-9.3$ \\
\hline Vitamin A rich fruits and vegetables & 70 & 33.3 & $26.0-41.5$ \\
\hline Other fruits and vegetables & 117 & 47.1 & $40.7-53.6$ \\
\hline Tea with sugar & 56 & 22.7 & $15.9-31.3$ \\
\hline
\end{tabular}

Consumption of vegetables and fruits was also insufficient. Dairy products (milk, yogurt, cheese and other dairy products) were included in the diet of $75.6 \%$ (95\% CI $69.2-81.0)$ of
6-23 month-old children during the previous day $(p<0.003)$. Consumption of dairy products among 6-23 month-old surveyed children by region is demonstrated in Table 4.

Table 4. Proportion of children aged 6-23 months whose diet includes milk and dairy products, by region

\begin{tabular}{|l|c|c|c|}
\hline \multirow{2}{*}{ Region } & \multicolumn{3}{|c|}{ Consumption of dairy products } \\
\cline { 2 - 4 } & $\mathrm{n}$ & $\%$ & $95 \% \mathrm{CI}$ \\
\hline Western & 112 & 80.4 & $60.1-91.8$ \\
\hline Khangai & 115 & 78.6 & $63.5-88.6$ \\
\hline Central & 83 & 79.6 & $66.0-88.7$ \\
\hline Eastern & 99 & 68.7 & $53.3-80.9$ \\
\hline Ulaanbaatar & 86 & 72.0 & $60.3-81.4$ \\
\hline
\end{tabular}

Consumption of dairy products is below the average in Ulaanbaatar (72\%) and Eastern Province (68.7\%). The indicator was significantly lower in urban $(68.3 \%, 95 \% \mathrm{CI}$ $59.6-75.9)$ as opposed to rural $(86.4 \%, 95 \% \mathrm{CI}$ 79.5-91.2) children aged 6-23 months.

There was a trend towards decrease in the consumption of dairy products with age. For instance, $68.2 \%(95 \% \mathrm{CI} 55.4-78.8)$ of 6-11 month old children, $80.4 \% \quad(95 \% \mathrm{CI}$ $71.1-87.2)$ of $12-17$ month old children, and $76.5 \%$ (95\% CI $66.4-84.3)$ of $18-23$ month old children received dairy products during the previous day. Only $48.7 \%$ (95\%CI $37.9-59.5)$ of children with vitamin D deficiency were consumed milk and dairy products during the previous day of survey data collection. Of the surveyed 6-23 month-old children with complementary feeding, $47.1 \%$ (95\%CI 40.753.6) received other vegetables and fruits during the previous day (vegetables and fruits other than carrots, pumpkin, tomato, green pepper, spinach and kiwi). Consumption of other type of vegetable and fruit consumption in 6-23 month-old children was compared between regions (Table 5). 
Table 5. Proportion of children aged 6-23 months whose diet includes other fruits and vegetables, by region

\begin{tabular}{|l|c|c|c|}
\hline \multirow{2}{*}{ Region } & \multicolumn{3}{|c|}{ Consumption of other vegetables and fruits } \\
\cline { 2 - 4 } & $\mathrm{n}$ & $\%$ & $95 \% \mathrm{CI}$ \\
\hline Western & 18 & 13.0 & $6.9-23.3$ \\
\hline Khangai & 50 & 53.6 & $39.8-66.8$ \\
\hline Central & 66 & 70.4 & $57.3-80.8$ \\
\hline Eastern & 54 & 31.2 & $21.2-43.5$ \\
\hline Ulaanbaatar & 72 & 46.0 & $33.6-58.9$ \\
\hline
\end{tabular}

Consumption of other type of vegetables and fruits was significantly lower in Western Region, and significantly higher in Central Region compared to other regions.

According to the place of residence, $48.8 \%$ $(95 \%$ CI $39.7-57.9)$ of urban $6-23$ month old children and $44.6 \%$ (95\% CI 35.6-53.9) of their rural counterparts had a diet, which included vegetables and fruits other than carrots, pumpkin, tomato, green pepper, spinach and kiwi. When broken down by age, $31.7 \%$
(95\%CI 22.3-43.0) of children aged 6-11 months, $53.1 \%(95 \%$ CI $42.2-63.7)$ of those aged 12-17 months, and 54.4\% (95\%CI 42.665.6) of those aged 18-23 months consumed other vegetables and fruits.

Dietary diversity in children 6-23 months of age: Of 6-23 month-old children with complementary feeding, $52.1 \%(95 \%$ CI 45.3 58.8) met the WHO criteria for minimum dietary diversity (Table 6).

Table 6. Proportion of children aged 6-23 months, who received foods from 4 and more groups, by region

\begin{tabular}{|l|c|c|c|c|}
\hline \multirow{2}{*}{\multicolumn{1}{c|}{ Region }} & \multirow{2}{*}{$\mathrm{N}$} & \multicolumn{3}{c|}{ Children received 4 and more food groups } \\
\cline { 3 - 5 } & & $\mathrm{n}$ & $\%$ & $95 \% \mathrm{CI}$ \\
\hline Western & 46 & 12 & 26.1 & $14.8-41.8$ \\
\hline Khangai & 56 & 28 & 50.0 & $35.3-64.7$ \\
\hline Central & 52 & 33 & 63.5 & $49.3-75.6$ \\
\hline Eastern & 64 & 15 & 23.4 & $15.2-34.4$ \\
\hline Ulaanbaatar & 50 & 32 & 64.0 & $50.5-75.6$ \\
\hline
\end{tabular}

Proportion of children aged 6-23 months, who received foods from 4 and more groups is insufficient in western and eastern regions. Particularly, proportion of children aged 6-23 months who receive 4 and more food groups in eastern regions statistically significantly lover that compared to Khangai and Central regions and Ulaanbaatar. By age group, the proportion of children with minimum dietary diversity was $32.4 \%$ (95\%CI 21.4- 45.9) in 6-11 month old children, $62.9 \%$ (95\% CI 53.3-71.6) in $12-$ 17 month old children, and $57.3 \%(95 \% \mathrm{CI}$ 45.6-68.3) in 18-23 month old children. Only $37.4 \%$ (95\%CI $30.3-45.1)$ of anaemic, $48.7 \%$ (95\%CI 37.9-59.5) of vitamin D deficient, and $51.6 \%(95 \% \mathrm{CI} 43.2-59.9)$ of vitamin A deficient children were received foods 4 and more groups in compliance with WHO recommendations. 
Table 7. Types of complementary food

\begin{tabular}{|l|ccc|}
\hline \multirow{2}{*}{ Types of complementary foods } & \multicolumn{3}{c|}{ 6-23 months old children } \\
\cline { 2 - 4 } & $\mathrm{n}$ & $\%$ & $95 \% \mathrm{CI}$ \\
\hline Semolina porridge & 61 & 25.1 & $17.9-33.9$ \\
\hline Porridges & 14 & 4.8 & $2.6-8.7$ \\
\hline Yogurt & 144 & 51.2 & $43.7-58.6$ \\
\hline Meat and flour porridge (Bantan*) & 138 & 54.7 & $48.0-61.3$ \\
\hline Vegetable/fruit puree & 19 & 9.0 & $5.1-15.5$ \\
\hline Vegetable/fruit juice & 27 & 10.7 & $7.1-15.7$ \\
\hline Dishes for other household members & 206 & 78.5 & $72.8-83.3$ \\
\hline Bakery & 14 & 5.8 & $3.1-10.7$ \\
\hline Milk & 2 & 0.8 & $0.1-5.7$ \\
\hline Other & 4 & 0.9 & $0.3-2.6$ \\
\hline
\end{tabular}

As Shown in Table 7, 78.5 percent of children aged 6-23 months who should receive separately cooked meals, were fed with family foods. For this age group children meat and flour porridge, dishes cooked for other household members and yogurt remained the predominant types of complementary food.
Consumption of food rich in vitamin A: Of the surveyed children aged 0-59 months, $35.5 \%$ (95\% CI 30.7-40.5) consumed food rich in vitamin A (food rich in vitamin A was defined as carrots, pumpkin, tomato, green pepper, spinach and kiwi). In 6-23 month old children, the proportion was $33.3 \%(95 \% \mathrm{CI}$ 26.1-41.5).

Table 8. Proportion of children aged 6-23 months whose diet includes food rich in vitamin A, by region

\begin{tabular}{|l|c|c|c|}
\hline \multirow{2}{*}{ Region } & \multicolumn{3}{|c|}{ Consumption of food rich in vitamin A } \\
\cline { 2 - 4 } & $\mathrm{n}$ & $\%$ & $95 \% \mathrm{CI}$ \\
\hline Western & 31 & 21.7 & $9.7-41.8$ \\
\hline Khangai & 21 & 12.5 & $5.2-27.0$ \\
\hline Central & 33 & 35.2 & $21.5-51.9$ \\
\hline Eastern & 24 & 10.9 & $5.2-21.6$ \\
\hline Ulaanbaatar & 81 & 54.0 & $37.7-69.5$ \\
\hline
\end{tabular}

Consumption of food rich in vitamin A among children aged 6-23 months was higher in Ulaanbaatar and Central Region compared to other regions. The differences between Ulaanbaatar and the other regions were all statistically significant. Only the differences between Central Region and Khangai and Eastern Region and Ulaanbaatar were statistically significant (Table 4). Urban 6-23 month-old children were substantially more likely to receive food rich in vitamin A $(44.5 \%, 95 \% \mathrm{CI} 33.6-56.0)$ compared to their rural counterparts $(16.5 \%, 95 \% \mathrm{CI} 9.5-27.1)$. The consumption of foods rich in vitamin $\mathrm{A}$ increased with age: $25.4 \%$ (95\%CI 16.1-37.5) in 6-11 month old children, 32.3\% (95\%CI 21.9-44.9) in 12-17 month old children, and $42.1 \%(95 \%$ CI $29.7-55.6)$ in $18-23$ month old children. More than half $(51.9 \%, 95 \%$ CI $41.6-$ 62.1) of surveyed children with vitamin A deficiency were received fruits and vegetables rich in vitamin $\mathrm{A}$.

Practice of cooking separate complementary meals for children: Overall, -61 - 
$70.0 \%$ (95\% CI 63.2-76.1) of 6-23 month-old children for whom meals need to be cooked separately, receive such complementary feeding.

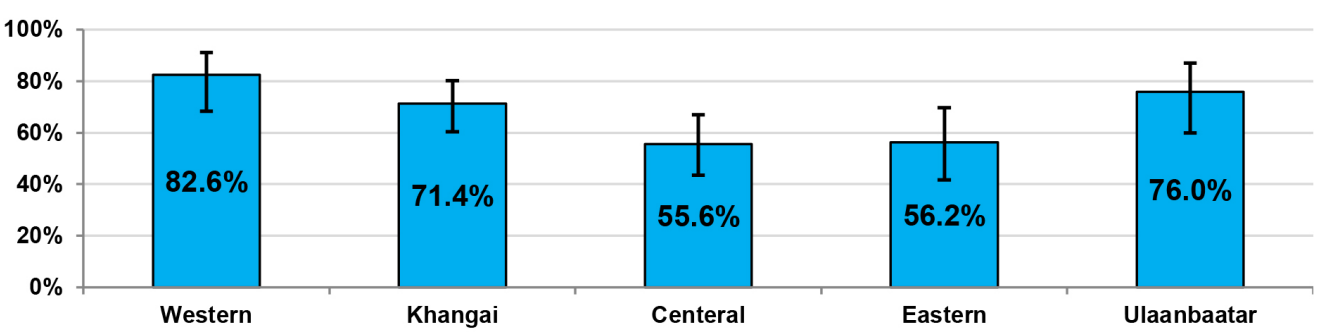

Figure 3. Proportion of children who receive meals separately prepared, by region

The proportion of children who receive separate meals was highest in Western Region and Ulaanbaatar and lowest in Central Region and Eastern Region. The proportion was statistically significantly higher in Western as compared to Central and Eastern Regions (Figure 3). The practice of cooking separate complementary meals for 6-23 month-old children was found in the caregivers of $76.4 \%$ (95\% CI 66.1-84.4) of urban children and $60.4 \%$ (95\% CI 52.9-67.5) of rural children.
Complementary meals were cooked separately for $53.8 \%$ (95\% CI 44.4-63.0) of children with anemia, 33.3\% (95\%CI 25.2-42.6) of children with vitamin $\mathrm{D}$ deficiency, and $34.5 \%$ (95\% CI 23.8- 47.0) of children with vitamin A deficiency. Complementary meals were cooked separately for $53.8 \%(95 \% \mathrm{CI}$ 44.4-63.0) of children with anemia, 33.3\% (95\% CI 25.2-42.6) of children with vitamin D deficiency, and $34.5 \%$ (95\% CI 23.8-47.0) of children with vitamin A deficiency.

\section{DISCUSSION}

Early initiation of breastfeeding, exclusive breastfeeding for six months, and timely introduction of age-appropriate complementary feeding are the key interventions to achieve the Millennium Development Goal 1 and 4, which address child malnutrition component of the targets and mortality respectively3. Indicators for Assessing Infant and Young Child Feeding Practices (2007) were revised during the International Consensus Meeting organized by WHO in 2007. The Fourth National Nutrition Survey differs from the previous surveys not only in scope and sampling, but also in using these revised indicators for the assessment of child feeding practices. For this reason, some of the findings of the Fourth National Nutrition Survey could not be compared to previous survey findings. Nutritional indicators estimated

using the same methods as in the previous surveys were compared to the latter.
Similarly, findings related to breastfeeding and complementary feeding were compared to the results of MICS survey and Survey on Caregivers' Knowledge, Attitude and Practice Regarding Young Child Feeding (2010) conducted using analogous methods.

The prevalence of early initiation of breastfeeding found in NNS IV is similar to the findings of the previous national nutrition surveys. In 1999, the proportion of newborns put to the breast within 30 minute of the birth was $93.4 \%$. In $2004,83.5 \%$ of newborns were put to the breast within 1 hour of the birth. The prevalence of exclusive breastfeeding in NNS IV demonstrates an increase from the estimate of $57 \%$ found in the MICS survey in 2005 conducted by National Statistics Office20.The prevalence rates of continued breastfeeding at 1 and 2 years of age were slightly less than those found in MICS survey $(83.2 \%$ at 1 year and $64.5 \%$ at 2 years). An improvement in 
nutritional indicators was observed in Western Region since the MICS survey in 2005. For instance, early breastfeeding increased from $73.8 \%$ to $93.7 \%$, exclusive breastfeeding increased

from $54.7 \%$ to $76.5 \%$, and continued breastfeeding at 1 year increased from $90.0 \%$ to $100 \%$ between 2005 and the current survey. Such an improvement could be attributed to increased attention of the Government and international partners to child nutrition in this region in the past few years. The NNS

\section{CONCLUSION}

The main problems revealed from the study were inappropriate complementary feeding practices. Exclusive breastfeeding was $71.3 \%$, continued breastfeeding at 1 year was $74.0 \%$, and continued breastfeeding at 2 years was $54.6 \%$ were decreased. $28.7 \%$ of the surveyed children below 6 months were initiated complementary feeding too early. Although more than $50 \%$ of $6-23$ month-olds received foods from 4 or more food groups according to WHO recommendations, the dietary diversity

\section{Acknowledgement}

The authors gratefully acknowledge the financial support rendered by Ministry of Health, Ministry of Food, Agriculture and Light Industry and United Nations Children's
IV finding that complementary feeding was introduced earlier than recommended in almost one third of children corresponds to the results of the Survey on Caregivers' Knowledge, Attitude and Practice Regarding Young Child Feeding done in 2010, in which $26.3 \%$ of children had early introduction of complementary feeding. The results of the current survey highlighted the importance of improving caregivers' knowledge, attitude and practice regarding young child care and proper feeding.

of complementary food was inadequate for children aged 6-23 months.

The majority of the surveyed children were fed 3-4 times a day in compliance with WHO recommendations. The indicator was 4060 percent in Western and Eastern Regions. Our findings have highlighted the need to encourage mothers to enrich their traditional wheat- based complementary foods add more animal source foods and vegetables.

Fund, World Health Organization, World Vision Mongolia International NGO and with the technical assistance of Dr. Bradley A. Woodruff, international consultant. 


\section{REFERENCES}

1. American Academy of Pediatrics Committee on Nutrition. Pediatric Nutrition Handbook. Fifth. 2004

2. World Health Organization. Global strategy for infant and young child feeding. Geneva: World Health Organization, 2003. 41 p.

3. Bhutta ZA, Ahmed T, Black RE, Cousens S, Dewey K, Giugliani E et al. What works? Interventions for maternal and child undernutrition and survival. Lancet 2008;371:41740.

4. Black RE, Morris SS, Bryce J. Where and why are 10 million children dying every year? Lancet 2003;361:2226-34.

5. Saha KK, Frongillo EA, Alam DS, Ariffen SE, Persson LA, Rasmussen KM. Appropriate infant feeding practices result in better growth of infants and young children in rural Bangladesh. Am J Clin Nutr 2008;87:1852-9.

6. Jones G, Steketee RW, Black RE, Bhutta ZA, Morris SS; Bellagio Child Survival Study Group. How many child deaths can we prevent this year? Lancet 2003;362:65- 71.

7. World Health Organization. Complementary feeding of young children in developing countries: a review of current scientific knowledge. Geneva: World Health Organization, 1998. $237 \mathrm{p}$.

8. Hop LT, Gross R, Giay T, Sastroamidjojo S, Schultink W, Lang NT. Premature complementary feeding is associated with poorer growth of Vietnamese children. J Nutr 2000;130:2683-90.

9. Feachem $R G$, Koblinsky MA. Interventions lor the control of diarrhoeal diseases among young children: promotion of breast-feeding. Bull World Health Organ 1984;62:271-91.

10. Asha Bai PV, Leela M, Subramaniam VR. Adequacy of breast milk for optimal growth of infants. Trop Geogr Med 1980:32:158-61

11. Grummer-Strawn LM. Does prolonged breastfeeding impair child growth? A critical review Pediatrics 1993;91:766-71

12. Victora CG, Vaughan JP, Martines JC, Barcelos LB. Is prolonged breastfeeding associated with malnutrition? Am J CUn Nulr 1984;39:307-14.

13. Brakohiapa LA, Yartey J, Bille A et al. Does prolonged breastfeeding adversely affect a child's nutritional status? Lancet 1988:1:416-18.

14. Taren D, Chen J. A positive association between extended breastfeeding and nutritional status in rural Hubei Province, People's Republic of China. Am J Clin Nutr 1993:58:86267.

15. Rao S, Kande AN. Prolonged Breastfeeding and malnutrition among rural Indian children below 3 years of age Europ J Clm Nutr 1992; 46:187-95.

16. Caulfield LE, Bentley ME, Ahmed S. Is prolonged breastfeeding associated with malnutrition? Evidence from nineteen Demographic and Health Surveys. Int J Epidemiol 1996:25:693-703.

17. Nutritional Status of Mongolian Children and Women: Third National Nutrition Survey Report. NRC, UNICEF, and MOH Mongolia; Ulaanbaatar, 2004-2006.

18. Bhutta ZA, Ahmed T, Black RE, Cousens S, Dewey K, Giugliani E et al. What works? Interventions for maternal and child undernutrition and survival. Lancet 2008;371:41740.

19. World Health Organization. Indicators for assessing infant and young child feeding practices: conclusion of a consensus meeting, held on 6-8 November 2007 in Washington, DC, USA. Geneva: World Health Organization, 2008. 19 p.

20. Child and Development 2005 Survey (Multiple Indicator Cluster Survey 3: Final Report. Mongolia NSO, UNICEF; Ulaanbaatar, 2007. 